\title{
Bio-Archive Core Storage and Subsampling Procedure for Subseafloor Molecular Biological Research
}

\author{
by Noriaki Masui, Yuki Morono, and Fumio Inagaki
}

doi:10.2204/iodp.sd.8.05.2009

\section{Introduction}

The Integrated Ocean Drilling Program (IODP) provides unprecedented opportunities to study the deep subseafloor biosphere. Subseafloor microbes play important roles in biogeochemical cycling of carbon, nitrogen, sulfur, metals, and other elements on geologic timescales; however, their growth and metabolic characteristics remain largely unknown because most subseafloor microbes are phylogenetically distinct from known isolates and resistant to culturing in laboratories. Given the significance of this region as potential habitats of subseafloor life, cored materials (or portions thereof) should be frozen in long-term storage to provide opportunities for future molecular analyses arising from rapid biotechnological developments (D’Hondt et al., 2007). Here we report a semi-aseptic subsampling technique for frozen core samples using an electric saw system in a clean booth. This subsampling technique enables us to share and distribute samples from the same depth for multiple analyses, such as DNA and lipid biomarkers, without thawing the frozen core.

\section{Problems with Current Storage Conditions}

The activity of subseafloor microbial life is generally very slow (D'Hondt et al., 2002, 2004); however, it impacts biogeochemical cycling on Earth on geological timescales, and moreover it provides clues for understanding the origin and evolution of life. Microscopic observations as well as molecular (e.g., DNA) surveys demonstrate widespread microbial presence in the marine subsurface environment (Parkes et al., 1994, 2000; Inagaki et al., 2006; Lipp et al., 2008; Morono et al., 2009). Given the significance of cored materials for studying deep subseafloor life and the biosphere, legacy samples called "Bio-archives" are extremely useful for studying distributions of biomass, diversity, community composition, habitability, and metabolic activity. To achieve bio-archive storage and sample distribution, new sampling techniques are in high demand to minimize damage and contamination.

During the long history of scientific drilling, most cores have been stored at room temperature or around $4^{\circ} \mathrm{C}$ in open storage rooms. However, contaminating microbes from the air or scientists themselves easily grew under these storage conditions (Fig. 1) and thus caused critical damage to core quality. Oxygen penetration stimulates growth of contaminating aerobic bacteria as well as germination of buried fungal and bacterial spores. Since aerobic bacteria grow on organic matter in cored sediments, the dramatic change in conditions during storage easily kills subseafloor microbial life. After cell death, fragile bio-molecules such as RNA, enzymes, sugar chains, and intact polar lipids rapidly degrade via abiotic hydrolysis and enzymatic reactions, subsequently promoting the activity of contaminating microbes. In addition to preventing such degradation, freezing cores also prevents dissolution of carbonates during long-term storage and hence maintains the fine textures of carbonate fossils. Therefore, preserving frozen core materials under appropriate conditions is necessary for microbiological and biogeochemical studies.

\section{Electric Band Saw System}

During previous ODP/IODP expeditions, most microbiological samples were obtained as whole round cores (WRC) and stored at $-80^{\circ} \mathrm{C}$. One of the difficulties of frozen WRC handling is subsampling for molecular biological or biogeochemical analyses in shore-based laboratories. In the past, to

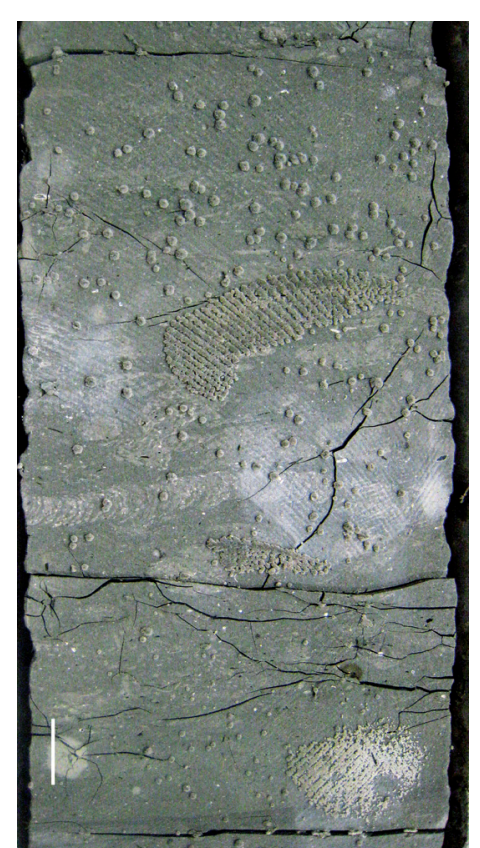

Figure 1. An example of contaminating microbial colonies growing on the core surface after long-term storage (ID: 190-1174B-63R-3W). Bar indicates $1 \mathrm{~cm}$. collect subsamples from a frozen WRC, cores were thawed on a clean bench, then an innermost sample was collected using a heat-sterilized spatula or an autoclaved tip-cut syringe, and the rest of the sample was returned to the deep freezer for subsequent analyses. This freeze-thaw cycle enhanced damage of endolithic and sedimentary biomolecules and increased the probability of experimental contamination. Alternatively, frozen cores could be manually broken with a heat-sterilized chisel without the risk of melting; however, collecting the innermost part of the core that had avoided 

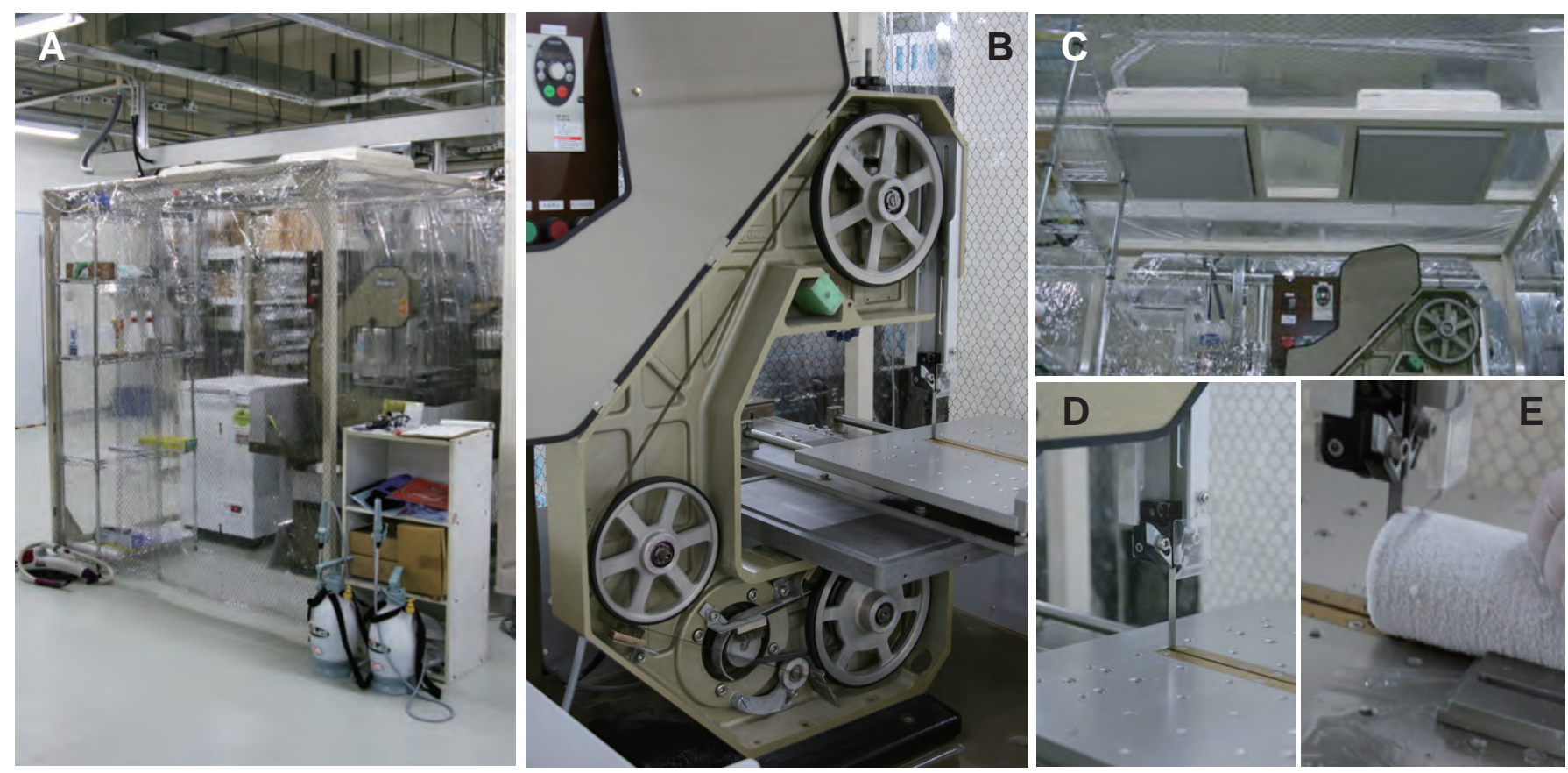

Figure 2. [A]Overview of the electric band saw system for microbiological frozen core. Motor-driven electric band saw machine $[\mathrm{B}]$ and $-50^{\circ} \mathrm{C}$ freezer is deployed in a clean booth equipped with two HEPA-filter units [C]. Diamond-tipped band saw cuts frozen core samples under clean conditions [D, E].

potential drilling fluid contamination was difficult.

For better analytical use of frozen WRC and other types of frozen geological materials such as rocks and sediments, we constructed a semi-aseptic electric band saw system. A diamond powder-etched band saw machine (RYOWA Co. Ltd., Japan) and a $-50^{\circ} \mathrm{C}$ freezer for temporary core storage were set up in a clean booth equipped with two HEPA-filter units (Model ATML-2-E252, NIPPON MUKI Co. Ltd., Japan)

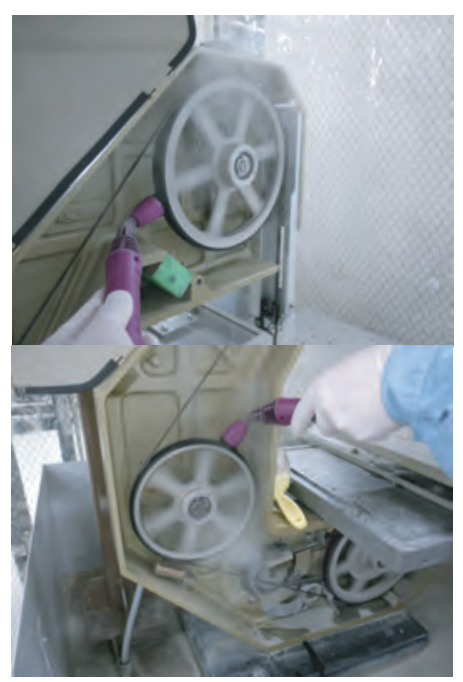

Figure 3. Cleaning run. Band saw and three wheels must first be cleaned with heat-steam followed by an ethanol spray-wash and a Milli-Q rinse.
(Fig. 2). The electric saw

smoothly cuts frozen WRCs under clean air in a short time without melting the core. In standard applications, the electric band saw is cooled with water to prevent frictional heat buildup; however, this step is not necessary for frozen cores, which are even better for maintaining aseptic conditions. Cutting the frozen core also eases multiple rounds of subsampling without disturbing the stratigraphic conditions. To prevent cross-contamination, it is necessary to clean the saw's parts, such as the saw blade and its wheels, using a steam-heat cleaner (Fig. 3) followed by an ethanol spray and a Milli-Q water rinse.

\section{Example of Frozen Whole Round Core Subsampling Possibilities}

The electric saw system described herein enables quick subsampling of frozen cores into various shapes. For examples, the frozen WRC is first cut in half vertically, and one of the halves is cut into a plate shape (Fig. 4). Then the plate can be cut into bars ( $5 \mathrm{~mm} \times 10 \mathrm{~mm}$ ). A 6.5-cm-diameter core, which is the usual ODP/IODP core size, yields forty-six of these subsampled bars. As many of the frozen bar samples as needed can be used for molecular analyses. For experiments requiring larger volumes, half of the WRC may be used. Overall, this protocol is flexible with respect to subsample volume, and it eases sharing the exact same horizon among multiple analyses.

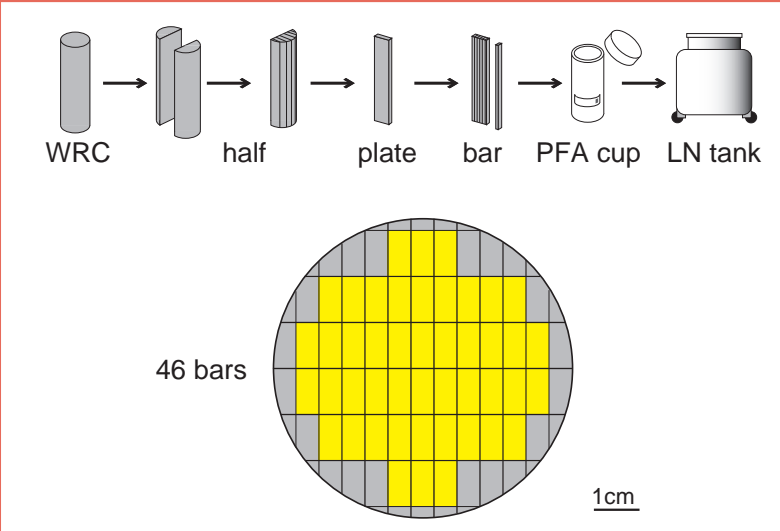

Figure 4. An example of frozen whole round core (WRC) subsampling. The WRC is first cut in half lengthwise, then one half is sectioned into plates, and each plate is cut into bars. Cut core samples are put in PFA cups and stored in a liquid nitrogen tank at $-160^{\circ} \mathrm{C}$ (or deep freezer at $-80^{\circ} \mathrm{C}$ ) 


\section{Storage of Frozen Bioarchives}

For optimal preservation, the initial freezing step is important. Flash freezing with liquid nitrogen (LN) is better than normal (slow) freezing. Cores should then ideally be subsampled with the electric saw system and stored either in a LN tank or $-80^{\circ} \mathrm{C}$ deep freezer until examined. For effective preservation of RNA, the sample should be put into a commercial RNA-stabilizing solution (e.g., RNAlater ${ }^{\circledR}$, Ambion), the supernatant removed after several hours' incubation at $4^{\circ} \mathrm{C}$, and then the sample put into the deep freezer. RNAlater ${ }^{\circledR}$-ICE (Ambion) may be useful for recovering RNA from frozen samples during thawing. Sample preservation in acetone may be an alternative method to preserve RNA (Fukatsu, 1999).

For long-term storage we are currently performing trials using a LN tank (Fig. 3), whose (gas phase) temperature is approximately $-160^{\circ} \mathrm{C}$ ( $\mathrm{T}$ liquid phase $=-196^{\circ} \mathrm{C}$ ). It is well recognized that lower temperatures are better for long-term storage of fragile biomolecules, and an oxygen-free nitrogen atmosphere is suitable for preserving oxygen-sensitive enzymes and anaerobic microbes. For samples stored in a LN tank, a cup made of PFA (perfluoroalkoxylalkane) is the best choice despite its price, because PFA withstands temperatures ranging from $-196^{\circ} \mathrm{C}$ to $200^{\circ} \mathrm{C}$ and hence is also autoclavable. PFA cups are also useful for storing methane hydrate samples; liquid nitrogen can be poured directly on the samples in a cup. These options should be practiced onboard in order to preserve biological samples most effectively.

\section{Future Developments}

Several possibilities are conceivable for future uses of bioarchived cores. First, if this electric saw system can be deployed on drilling platforms, frozen samples at the same horizons can be distributed among researchers, and the rest can be returned for sedimentological and paleontological studies or standard archiving. This process will minimize sample volume and avoid sample location differences among multiple analyses; however, we need to modify the system for ease of use, smaller sample sizes, and reduced costs. The cleaning step must be modified to save time and to simplify its execution. In addition, we are currently testing an improved mini-core sampling system using an autoclavable metal tube with a saw tip, which allows onboard subsampling not only of frozen samples but also of hard rocks.

\section{Acknowledgements}

The authors thank K. Aoike (JAMSTEC-CDES) and RYOWA Co. Ltd. for useful suggestions on the electric saw system, and T. Terada (Marine Works Japan, Ltd.) for technical assistance. The photographic data was provided by the ODP/IODP.

\section{References}

D’Hondt, S., Inagaki, F., Ferdelman, T., Jørgensen, B.B., Kato, K., Kemp, P., Sobecky, P., Sogin, M., and Takai, K., 2007. Workshop Report: Exploring subseafloor life with the Integrated Ocean Drilling Program. Sci. Drilling, 5:26-37.

D'Hondt S., Jørgensen, B.B., Miller, D.J., Batzke, A., Blake, R., Cragg, B.A., Cypionka, H., Dickens, G.R., Ferdelman, T., Hinrichs, K.U., Holm, N.G., Mitterer, R., Spivack, A., Wang, G.Z., Bekins, B., Engelen, B., Ford, K., Gettemy, G., Rutherford, S.D., Sass, H., Skilbeck, C.G., Aiello, I.W., Guerin, G., House, C.H., Inagaki, F., Meister, P., Naehr, T., Niitsuma, S., Parkes, R.J., Schippers, A., Smith, D.C., Teske, A., Wiegel, J., Padilla, C.N., and Acosta, J.L.S., 2004. Distributions of microbial activities in deep subseafloor sediments. Science, 306:2216 2221, doi:10.1126/science.1101155.

D’Hondt, S., Rutherford, S., and Spivack, A.J., 2000. Metabolic activity of subsurface life in deep-sea sediments. Science, 295:2067-2070, doi:10.1126/science.1064878.

Fukatsu, T., 1999. Acetone preservation: a practical technique for molecular analysis. Mol. Ecol., 8:1935-1945, doi:10.1046/ j.1365-294x.1999.00795.x.

Inagaki, F., Nunoura, T., Nakagawa, S., Teske, A., Lever, M., Lauer, A., Suzuki, M., Takai, K., Delwiche, M., Colwell, F.S., Nealson, K.H., Horikoshi, K., D’Hondt, S., Jørgensen, B.B., 2006. Biogeographical distribution and diversity of microbes in methane hydrate-bearing deep marine sediments on the Pacific Ocean Margin. Proc. Natl. Acad. Sci. U.S.A., 103:2815-2820, doi:10.1073/pnas.0511033103.

Lipp, J.S., Morono, Y., Inagaki, F., and Hinrichs, K.-U., 2008. Significant contribution of Archaea to extant biomass in marine subsurface sediments. Nature, 454:991-994, doi:10.1038/nature07174.

Morono, Y., Terada, T., Masui, N., and Inagaki, F., 2009. Discriminative detection and enumeration of microbial life in marine sediments. ISME J., 3 :503-511, doi:10.1038/ismej.2009.1.

Parkes, R.J., Bragg, B.A., and Wellsbury, P., 2000. Recent studies on bacterial populations and processes in subseafloor sediments: A review. Hydrogeol. J., 8:11-28, doi:10.1007/ PL00010971.

Parkes, R.J., Cragg, B.A., Bale, S.J., Getliff, J.M., Goodman, K., Rochelle, P.A., Fry, J.C., Weightman, A.J., and Harvey, S.M., 1994. Deep bacterial biosphere in Pacific Ocean sediments. Nature (London, U. K.), 371:410-413, doi:10.1038/371410a0.

\section{Authors}

Noriaki Masui, Yuki Morono, and Fumio Inagaki, Geomicrobiology Group, Kochi Institute for Core Sample Research, Japan Agency for Marine-Earth Science and Technology (JAMSTEC), Monobe B200, Nankoku, Kochi 783-8502, Japan, e-mail: inagaki@jamstec.go.jp. 